\title{
Efficient Control of a Three Phase Grid Connected PV System
}

\author{
Hicham Bahri ${ }^{*}{ }^{1}$, Mohamed Bahri ${ }^{2}$, Mohamed Aboulfatah ${ }^{2}$, M'hammed Guisser $^{2}$,El malah Mohammed $^{2}$, and Oluwaseun \\ Simon Adekanle ${ }^{3}$
}

${ }^{1}$ Science Faculty Ben Msik, Laboratory of information processing, Hassan II University Casabalanca, Morocco

${ }^{2}$ Science and Technical Faculty of Settat, Department of Physics, Laboratory ASTI Hassan 1st University Settat, Morocco

${ }^{3}$ Higher School of Management Telecommunication and Informatique, Genius Laboratory Rabat, Morocco

\begin{abstract}
This paper presents a new control strategy of a photovoltaic system, which consists of a photovoltaic generator PVG coupled to a three phase load and three phase grid by a three phase voltage source inverter VSI without DC-DC converter. The controller is designed by using Backstepping method based on d-q transformation of a new model of the global system. The main goals of this control strategy are to achieve the maximum power point MPPT with very good precision and the unity power factor in level of the grid power flow. Mathematical analysis demonstrate the asymptotic stability of the controlled system and simulation results proved that the controller has achieved all the objectives with high dynamic performance in presence of atmospheric condition changes. Moreover, the proposed controller shows a very good robustness under system disturbance, which presents the most important advantage of this controller compared to the other control strategies. Furthermore, this controller can operate with a high efficiency with any kind of the load.
\end{abstract}

\section{Introduction}

Sustainable energy sources are a very good solution in the global energy problem. In this way, photovoltaic system is one of the most important energy solutions; the energy generated by photovoltaic system represents a large part of the total amount of energy produced by renewable energy sources [1], [2]. There are two types of photovoltaic systems which are the autonomous system and grid connected photovoltaic system. In the last years, the photovoltaic system connected to grid becomes more used due to need of supplying the world rise in demand for electric energy [3].

This paper presents an advanced control strategy using Backstepping method of a three phase grid connected photovoltaic system feeding non-linear load without DCDC converter. The main goals of this control strategy are: -Achieving the maximum power point tracking MPPT.

-Operation near the unity power factor.

-Control the power flow between the Photovoltaic Generator PVG and the grid.

There are many research efforts to realize these objectives [3]-[7]. But, they have not been able to achieve the goals with a good performance and they haven't considered all the constraints of the photovoltaic system (abrupt variation of climatic conditions and system's perturbation).
The proposed control strategy has achieved the MPPT with a very good precision and fast response time during abrupt atmospheric conditions changes. The controller permits also to compensate precisely the load reactive power, which guarantees the unity power factor operation of the system. Moreover, the proposed controller has presented a very good robustness in presence of system perturbation. Mathematical analysis and simulation results will demonstrate all the performance of this control strategy.

The next section of this paper presents the system description and mathematical model of the global system. Section III illustrates the control strategy of the studied system and gives a mathematical analysis. Section IV shows the simulation results. Finally, a short conclusion will be presented.

\section{System Description and modelling}

The system consists of a photovoltaic generator PVG coupled to a three phase grid via an input capacitor $C_{p}$, Voltage Source Inverter VSI and low pass filter (LR). A three phase load is coupled also to the system, this load can be supplied by the PVG power if it's enough, if it isn't

1 Corresponding author*: hbahri.inf@gmail.com 
enough the load will be supplied by the grid and the PVG at the same time. In case there is no sunlight, the load will be supplied by the grid and the inverter will just compensate the Reactive Power caused by the load. The proposed $\mathrm{PVG}$ system is given in figure 1 .

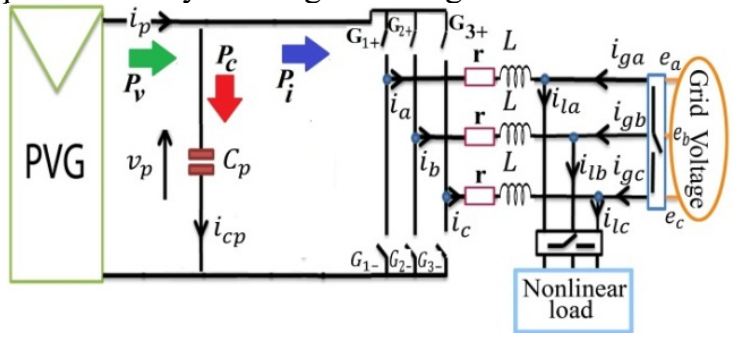

Fig. 1. Photovoltaic generator connected to a three phase grid feeding any kind of alternative load.

The PVG power $\mathrm{P}_{\mathrm{v}}$ is defined by:

$$
P_{v}=v_{p} \times i_{p}
$$

Where $v_{p}$ and $i_{p}$ are the PVG voltage and current. by:

The mathematical model of the studied system is given

$$
\left\{\begin{array}{l}
\frac{d v_{p}}{d t}=\frac{1}{C_{p}} \frac{P_{v}}{v_{p}}-\frac{1}{C_{p}} \frac{P_{i}}{v_{p}} \\
\frac{d i_{a}}{d t}=-\frac{r}{L} i_{a}-\frac{1}{L} e_{a}+\frac{1}{L} v_{a} \\
\frac{d i_{b}}{d t}=-\frac{r}{L} i_{b}-\frac{1}{L} e_{b}+\frac{1}{L} v_{b} \\
\frac{d i_{c}}{d t}=-\frac{r}{-} i_{c}-\frac{1}{-} e_{c}+\frac{1}{b} v_{c}
\end{array}\right.
$$

Where $\mathrm{P}_{\mathrm{i}}$ is the inverter Active Power, $\left(\mathrm{i}_{\mathrm{a}}, \mathrm{i}_{\mathrm{b}}, \mathrm{i}_{\mathrm{c}}\right)$ and $\left(\mathrm{v}_{\mathrm{a}}, \mathrm{v}_{\mathrm{b}}, \mathrm{v}_{\mathrm{c}}\right)$ are the inverter currents and voltages, $\left(\mathrm{e}_{\mathrm{a}}, \mathrm{e}_{\mathrm{b}}, \mathrm{e}_{\mathrm{c}}\right)$ are the grid voltages, $C_{p}$ is the imput capacitor, $L$ is the filter inductance and $r$ is the filter resistance

The park transformation of the previous model gives the following simplify model:

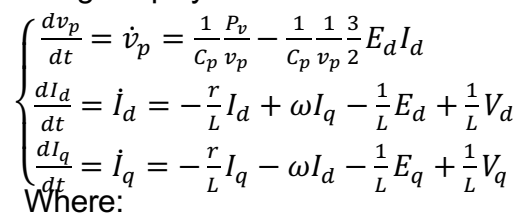

$$
\left(\begin{array}{c}
E_{d} \\
E_{q} \\
E_{0}
\end{array}\right)=\mathrm{P}_{\mathrm{abc}}^{\mathrm{dq0}}\left(\begin{array}{c}
e_{a} \\
e_{b} \\
e_{c}
\end{array}\right) ;\left(\begin{array}{c}
I_{d} \\
I_{q} \\
I_{0}
\end{array}\right)=\mathrm{P}_{\mathrm{abc}}^{\mathrm{dq0}}\left(\begin{array}{c}
i_{a} \\
i_{b} \\
i_{c}
\end{array}\right) ;\left(\begin{array}{c}
V_{d} \\
V_{q} \\
V_{0}
\end{array}\right)=\mathrm{P}_{\mathrm{abc}}^{\mathrm{dq0}}\left(\begin{array}{c}
v_{a} \\
v_{b} \\
v_{c}
\end{array}\right) \text {. }
$$

$\left(I_{d}, I_{q}\right)$ are the inverter current components in the $d-q$ axis, $\left(V_{d}, V_{q}\right)$ are the PWM references in the $d-q$ axis, $\left(E_{d}, E_{q}\right)$ are the grid voltages components in the $d-q$ axis and $\mathrm{w}$ is the grid pulsation.

With $\mathrm{P}_{\mathrm{abc}}^{\mathrm{dq0}}$ is the park's matrix transformation defined by [8]:

$$
\mathrm{P}_{\mathrm{abc}}^{\mathrm{dq} 0}=\frac{2}{3}\left(\begin{array}{ccc}
\sin (\theta) & \sin \left(\theta-\frac{2 \pi}{3}\right) & \sin \left(\theta-\frac{4 \pi}{3}\right) \\
\cos (\theta) & \cos \left(\theta-\frac{2 \pi}{3}\right) & \cos \left(\theta-\frac{4 \pi}{3}\right) \\
\frac{1}{2} & \frac{1}{2} & \frac{1}{2}
\end{array}\right)
$$

$\theta$ represents the phase angle of the grid calculated by the PLL technique [9].

After having modelling the system, the next section will illustrate the design of the control strategy.

\section{Control strategy}

The Backstepping method [10] has been selected to design a control strategy able to realize the following objectives with a very good performance and high robustness.

-Tracking the maximum point of the power produced by the PVG and convert all this power on Active Power.

-Compensate Reactive Power and harmonic distortion caused by the load.

All these goals must be achieved under abrupt atmospheric condition changes and system's perturbation (load harmonic pollution and system parameters disturbances)

\subsection{MPPT and Active Power controller}

The output selected to be controlled in order to achieve the MPPT is the derivative of the PVG power with respect to the PVG voltage defined by:

$$
\frac{\delta \mathrm{P}_{\mathrm{v}}}{\delta \mathrm{v}_{\mathrm{p}}}=\mathrm{i}_{\mathrm{p}}+\mathrm{v}_{\mathrm{p}} \frac{\partial \mathrm{i}_{\mathrm{p}}}{\partial \mathrm{v}_{\mathrm{p}}}
$$

This output must converge to zero in order to track the MPP with a very good precision [11], [12].

The Backstepping control law linked to the first output is developed as follows:

Firstly let's define the first tracking error as follows:

$$
\varepsilon_{1}=\frac{\delta \mathrm{P}_{\mathrm{v}}}{\delta \mathrm{v}_{\mathrm{p}}}-0=\mathrm{i}_{\mathrm{p}}+\mathrm{v}_{\mathrm{p}} \frac{\partial \mathrm{i}_{\mathrm{p}}}{\partial \mathrm{v}_{\mathrm{p}}}
$$

Using (3), the derivative of $\varepsilon_{1}$ can be developed as in (7):

$\dot{\varepsilon}_{1}=\left(2 \frac{\partial \mathrm{i}_{\mathrm{p}}}{\partial \mathrm{v}_{\mathrm{p}}}+\mathrm{v}_{\mathrm{p}} \frac{\partial^{2} \mathrm{i}_{\mathrm{p}}}{\partial \mathrm{v}_{\mathrm{p}}{ }^{2}}\right)\left(\frac{1}{\mathrm{C}_{\mathrm{p}}} \frac{\mathrm{P}_{\mathrm{v}}}{\mathrm{v}_{\mathrm{p}}}-\frac{1}{\mathrm{C}_{\mathrm{p}}} \frac{1}{\mathrm{v}_{\mathrm{p}}} \frac{3}{2} \mathrm{E}_{\mathrm{d}} \mathrm{I}_{\mathrm{d}}\right)$

The first Lyapunov function can be defined by:

$$
\mathrm{V}_{1}=\frac{1}{2} \varepsilon_{1}^{2}
$$

Its derivative is as follows:

$\left.\frac{1}{\mathrm{C}_{\mathrm{p}}} \frac{1}{\mathrm{v}_{\mathrm{p}}} \frac{3}{2} \mathrm{E}_{\mathrm{d}} \mathrm{I}_{\mathrm{d}}\right)$

$$
\dot{\mathrm{V}}_{1}=\varepsilon_{1} \dot{\varepsilon_{1}}=\varepsilon_{1}\left(2 \frac{\partial \mathrm{i}_{\mathrm{p}}}{\partial \mathrm{v}_{\mathrm{p}}}+\mathrm{v}_{\mathrm{p}} \frac{\partial^{2} \mathrm{i}_{\mathrm{p}}}{\partial \mathrm{v}_{\mathrm{p}}{ }^{2}}\right)\left(\frac{1}{\mathrm{C}_{\mathrm{p}}} \frac{\mathrm{P}_{\mathrm{v}}}{\mathrm{v}_{\mathrm{p}}}-\right.
$$

The derivative of the Lyapunov function must be negative. For that a virtual control law $\alpha$ is selected to get the following relation:

$$
\left(2 \frac{\partial \mathrm{i}_{\mathrm{p}}}{\partial \mathrm{v}_{\mathrm{p}}}+\mathrm{v}_{\mathrm{p}} \frac{\partial^{2} \mathrm{i}_{\mathrm{p}}}{\partial \mathrm{v}_{\mathrm{p}}{ }^{2}}\right)\left(\frac{1}{\mathrm{C}_{\mathrm{p}}} \frac{\mathrm{P}_{\mathrm{v}}}{\mathrm{v}_{\mathrm{p}}}-\frac{1}{\mathrm{C}_{\mathrm{p}}} \frac{1}{\mathrm{v}_{\mathrm{p}}} \frac{3}{2} \mathrm{E}_{\mathrm{d}} \alpha\right)=-\mathrm{k}_{1} \varepsilon_{1}
$$

Where:

$$
\alpha=\left(I_{d}\right)_{\text {desired }}
$$

$\mathrm{k}_{1}$ is a positive constant.

By using (10) the expression of $\alpha$ is:

$$
\alpha=\frac{-1}{\frac{13}{\mathrm{C}^{2}} \mathrm{E}_{\mathrm{d}}} \mathrm{v}_{\mathrm{p}}\left(\frac{-\mathrm{k}_{1} \varepsilon_{1}}{\left(2 \frac{\partial \mathrm{i}}{\partial \mathrm{v}_{\mathrm{p}}}+\mathrm{v}_{\mathrm{p}} \frac{\partial^{2} \mathrm{i} \mathrm{p}}{\partial \mathrm{v}_{\mathrm{p}}^{2}}\right)}-\frac{1}{\mathrm{C}_{\mathrm{p}}} \frac{\mathrm{P}_{\mathrm{v}}}{\mathrm{v}_{\mathrm{p}}}\right)
$$

The Derivative of $\alpha$ is:

$$
\begin{aligned}
& \dot{\alpha}=\frac{-1}{\frac{13}{\mathrm{C}_{\mathrm{p}}} \mathrm{E}_{\mathrm{d}}} \dot{\mathrm{v}}_{\mathrm{p}}\left(\frac{-\mathrm{k}_{1} \varepsilon_{1}}{\left(2 \frac{\partial \mathrm{i} p}{\partial \mathrm{v}_{\mathrm{p}}}+\mathrm{v}_{\mathrm{p}} \frac{\partial^{2} \mathrm{i} \mathrm{p}}{\partial \mathrm{v}_{\mathrm{p}}^{2}}\right)}-\frac{1}{\mathrm{C}_{\mathrm{p}}} \frac{\mathrm{P}_{\mathrm{v}}}{\mathrm{v}_{\mathrm{p}}}\right)-
\end{aligned}
$$

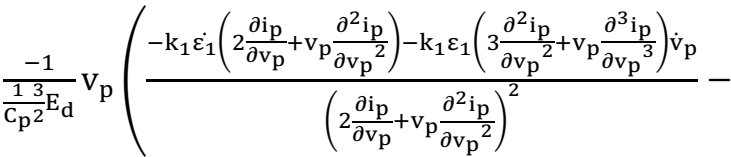




$$
\left.\frac{1}{\mathrm{C}_{\mathrm{p}}} \frac{\dot{\mathrm{P}_{\mathrm{v}} \mathrm{v}_{\mathrm{p}}-\mathrm{P}_{\mathrm{v}} \dot{\mathrm{v}}_{\mathrm{p}}}}{\mathrm{v}_{\mathrm{p}}{ }^{2}}\right)
$$

By applying this control law the derivative of the first Lyapunov function is necessarily negative and its expression is given by using (9), (10) and (11):

$$
\dot{\mathrm{V}}_{1}=-\mathrm{k}_{1} \varepsilon_{1}{ }^{2}
$$

Equation (12) supposes that the virtual control law $\alpha$ is equal to the current direct component $I_{d}$. But, in the reality there is an error between them. This error is defined by:

$$
\text { So, } \quad \varepsilon_{2}=\mathrm{I}_{\mathrm{d}}-\alpha
$$

By integrating (16) in (9) and using (10), the novel expression of $\dot{\mathrm{V}}_{1}$ is given by:

$$
\dot{\mathrm{V}}_{1}=-\mathrm{k}_{1} \varepsilon_{1}^{2}-\left(2 \frac{\partial \mathrm{i}_{\mathrm{p}}}{\partial \mathrm{v}_{\mathrm{p}}}+\mathrm{v}_{\mathrm{p}} \frac{\partial^{2} \mathrm{i}_{\mathrm{p}}}{\partial \mathrm{v}_{\mathrm{p}}{ }^{2}}\right) \frac{1}{\mathrm{C}_{\mathrm{p}}} \frac{1}{\mathrm{v}_{\mathrm{p}}} \frac{3}{2} \mathrm{E}_{\mathrm{d}} \varepsilon_{1} \varepsilon_{2}
$$

Therefore, $\dot{V}_{1}$ is no longer necessarily negative. For that a second Lyapunov function is proposed defined by:

$$
\mathrm{V}_{2}=\mathrm{V}_{1}+\frac{1}{2} \varepsilon_{2}^{2}
$$

Its derivative is given by:

$$
\dot{\mathrm{V}}_{2}=\dot{\mathrm{V}}_{1}+\varepsilon_{2} \dot{\varepsilon}_{2}
$$

By using (16) the derivative of $\varepsilon_{2}$ is given by:

$\dot{\varepsilon}_{2}=\dot{\mathrm{I}}_{\mathrm{d}}-\dot{\alpha}=-\frac{\mathrm{r}}{\mathrm{L}} \mathrm{I}_{\mathrm{d}}+\omega \mathrm{I}_{\mathrm{q}}-\frac{1}{\mathrm{~L}} \mathrm{E}_{\mathrm{d}}+\frac{1}{\mathrm{~L}} \mathrm{~V}_{\mathrm{d}}-\dot{\alpha}$

By integration (17) and (20) in (19) the final expression of $\dot{\mathrm{V}}_{2}$ is as follows:

$$
\begin{aligned}
& \dot{\mathrm{V}}_{2}=-\mathrm{k}_{1} \varepsilon_{1}^{2}-\left\lfloor( 2 \frac { \partial \mathrm { i } _ { \mathrm { p } } } { \partial \mathrm { v } _ { \mathrm { p } } } + \mathrm { v } _ { \mathrm { p } } \frac { \partial ^ { 2 } \mathrm { i } _ { \mathrm { p } } } { \partial \mathrm { v } _ { \mathrm { p } } { } ^ { 2 } } ) \frac { 1 } { \mathrm { C } _ { \mathrm { p } } } \frac { 1 } { \mathrm { v } _ { \mathrm { p } } } \frac { 3 } { 2 } \mathrm { E } _ { \mathrm { d } } \varepsilon _ { 1 } \left(-\frac{\mathrm{r}}{\mathrm{L}} \mathrm{I}_{\mathrm{d}}+\right.\right. \\
& \left.\left.\omega \mathrm{I}_{\mathrm{q}}-\frac{1}{\mathrm{~L}} \mathrm{E}_{\mathrm{d}}+\frac{1}{\mathrm{~L}} \mathrm{~V}_{\mathrm{d}}-\dot{\alpha}\right)\right\rfloor \varepsilon_{2}
\end{aligned}
$$

In order to stabilize $\varepsilon_{1}$ and $\varepsilon_{2}$ to zero, $\dot{\mathrm{V}}_{2}$ must be strictly negative. For this end, the following equality is imposed:

$$
\begin{gathered}
-\left(2 \frac{\partial \mathrm{i}_{\mathrm{p}}}{\partial \mathrm{v}_{\mathrm{p}}}+\mathrm{v}_{\mathrm{p}} \frac{\partial^{2} \mathrm{i}_{\mathrm{p}}}{\partial \mathrm{v}_{\mathrm{p}}^{2}}\right) \frac{1}{\mathrm{C}_{\mathrm{p}}} \frac{1}{\mathrm{v}_{\mathrm{p}}} \frac{3}{2} \mathrm{E}_{\mathrm{d}} \varepsilon_{1}+\left(-\frac{\mathrm{r}}{\mathrm{L}} \mathrm{I}_{\mathrm{d}}+\omega \mathrm{I}_{\mathrm{q}}-\right. \\
\left.\frac{1}{\mathrm{~L}} \mathrm{E}_{\mathrm{d}}+\frac{1}{\mathrm{~L}} \mathrm{~V}_{\mathrm{d}}-\dot{\alpha}\right)=
\end{gathered}
$$

$-\mathrm{k}_{2} \varepsilon_{2}$

Where $\mathrm{k}_{2}$ is a positive constant.

By integrating (22) into (21), the desired form of $\dot{V}_{2}$ is given by:

$$
\dot{\mathrm{V}}_{2}=-\mathrm{k}_{1} \varepsilon_{1}{ }^{2}-\mathrm{k}_{2} \varepsilon_{2}{ }^{2}
$$

By using (22) the expression of real control law which guarantees the desired form $\dot{V}_{2}$ is as follows:

$$
\begin{aligned}
& \mathrm{V}_{\mathrm{d}}=\mathrm{L}\left[-\mathrm{k}_{2} \varepsilon_{2}+\left(2 \frac{\partial \mathrm{i}_{\mathrm{p}}}{\partial \mathrm{v}_{\mathrm{p}}}+\mathrm{v}_{\mathrm{p}} \frac{\partial^{2} \mathrm{i}_{\mathrm{p}}}{\partial \mathrm{v}_{\mathrm{p}}{ }^{2}}\right) \frac{1}{\mathrm{C}_{\mathrm{p}}} \frac{1}{\mathrm{v}_{\mathrm{p}}} \frac{3}{2} \mathrm{E}_{\mathrm{d}} \varepsilon_{1}-\right. \\
& \left.\left(-\frac{\mathrm{r}}{\mathrm{L}} \mathrm{I}_{\mathrm{d}}+\omega \mathrm{I}_{\mathrm{q}}-\frac{1}{\mathrm{~L}} \mathrm{E}_{\mathrm{d}}-\dot{\alpha}\right)\right]
\end{aligned}
$$

By applying this control law, $\dot{\mathrm{V}}_{2}$ is necessarily negative and $\varepsilon_{1}$ converge asymptotically to zero, which guarantees the achievement of the MPPT with a very good precision and fast response time. Moreover, the input voltage is constant, therefore all the PVG power will be converted by the inverter on Active Power which means that the Active Power delivered by the inverter is maximized.

After have been maximized the inverter Active Power, the next step consists of controlling the inverter Reactive Power.

\subsection{Reactive Power controller}

The goal in this subsection is to compensate the Reactive Power caused by the load. For that, the inverter must inject Reactive Power $Q_{\mathrm{i}}$ equal to the Reactive Power caused by the load $Q_{L}$ in order to achieve the Unity power factor in the level of the power exchanges between the grid and the rest of the PVG system. The load and the inverter Reactive Power are given by using the mathematical expressions in dq0 frame as follows [13]:

Where:

$$
\begin{aligned}
Q_{L} & =-\frac{3}{2} E_{d} I_{q l} \\
Q_{i} & =-\frac{3}{2} E_{d} I_{q}
\end{aligned}
$$

$$
\left(\begin{array}{l}
I_{d l} \\
I_{q l} \\
I_{l 0}
\end{array}\right)=M_{a b c}^{d q 0}\left(\begin{array}{l}
i_{l a} \\
i_{l b} \\
i_{l c}
\end{array}\right)
$$

Knowing that the relation below must be achieved :

$$
Q_{i}=Q_{L}
$$

So, the reference $I_{\text {qref }}$ of the second output $I_{q}$ can be calculated by using (26) and (27) as follows:

$$
I_{\text {qref }}=-\frac{2}{3 E_{d}} Q_{L}
$$

The Backstepping controller of the second output $I_{q}$ is designed thereafter:

Let's define the following tracking error:

$$
\varepsilon_{3}=I_{q}-I_{q r e f}
$$

And its corresponding Lyapunov function:

$$
V_{3}=\frac{1}{2} \varepsilon_{3}{ }^{2}
$$

By using (29) and (30) the derivative of the Lyapunov function is given by:

$$
\dot{V}_{3}=\varepsilon_{3} \dot{\varepsilon}_{3}=\varepsilon_{3}\left(\dot{I}_{q}-\dot{I}_{\text {qref }}\right)
$$

This expression can be developed by using (3) of $\dot{\mathrm{I}}_{\mathrm{q}}$ as follows:

$$
\dot{I}_{\text {qref }} \dot{V}_{3}=\varepsilon_{3} \dot{\varepsilon}_{3}=\varepsilon_{3}\left(-\frac{r}{L} I_{q}-\omega I_{d}-\frac{1}{L} E_{q}+\frac{1}{L} V_{q}-\right.
$$

The derivative of $\dot{V}_{q}$ must be negative. For that the following relation is proposed:

$$
\begin{aligned}
& -\frac{r}{L} I_{q}-\omega I_{d}-\frac{1}{L} E_{q}+\frac{1}{L} V_{q}-\dot{I}_{q r e f}=-k_{3} \varepsilon_{3} \\
& \text { Where } \mathrm{k}_{3} \text { is a positive constant. }
\end{aligned}
$$

Therefore, the new expression of $\dot{V}_{\mathrm{q}}$ is given by using (32) and (33) as follows:

$$
\dot{V}_{3}=-k_{3} \varepsilon_{3}{ }^{2}
$$

So, $\dot{V}_{3}$ is negative.

By using (33), the control law $\mathrm{V}_{\mathrm{q}}$ is given by:

$$
V_{q}=L\left[-k_{3} \varepsilon_{3}+\omega I_{d}+\frac{r}{L} I_{q}+\frac{1}{L} E_{q}+\dot{I}_{\text {qref }}\right]
$$

The quadratic control law $\mathrm{V}_{\mathrm{q}}$ forces $\dot{\mathrm{V}}_{3}$ to be negative and $\varepsilon_{3}$ to converge to zero, which guarantees the asymptotic convergence of $\mathrm{I}_{\mathrm{q}}$ to its reference $\mathrm{I}_{\mathrm{qref}}$. And finally, the compensation of Reactive Power and harmonic component caused by load with a very good performance.

The following figure presents a block diagram of the PVG system and the Backstepping controller. 


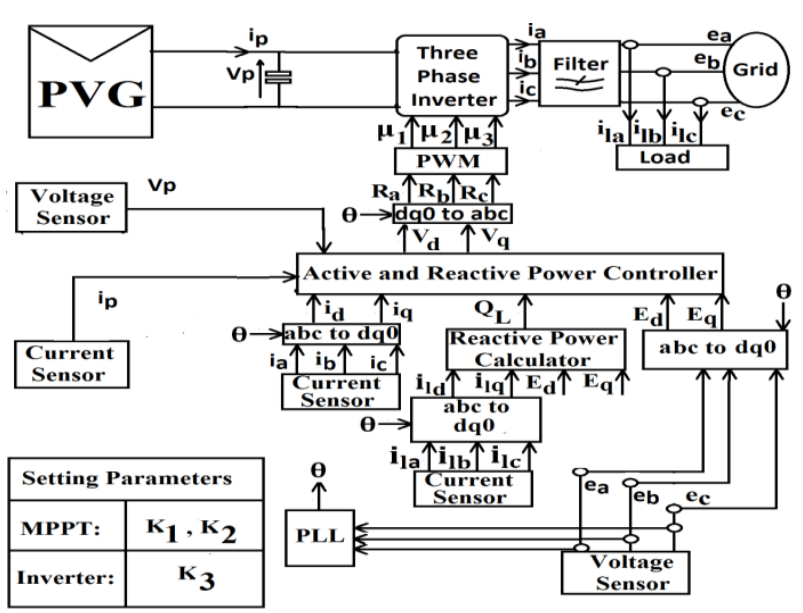

Fig. 2. Block diagram of the PVG system and the proposed Backstepping controller.

The control law $V_{d}$ and $V_{q}$ are used to generate the PWM references $R_{a}, R_{b}$ and $R_{c}$ by applying an inverse dq 0 transformation. The PWM outputs $\mu_{1}, \mu_{2}$ and $\mu_{3}$ are used to generate the switching signals of the inverter $\mathrm{G}_{1 \mp}, \mathrm{G}_{2 \mp}, \mathrm{G}_{3 \mp}$ able to achieve the controller objectives with a very good performance.

Where:

$$
\mu_{\mathrm{i}=1.3}=\left\{\begin{array}{l}
1 \rightarrow \mathrm{G}_{\mathrm{i}_{+}}: \text {on; } \mathrm{S}_{\mathrm{i}_{-}}: \text {off } \\
0 \rightarrow \mathrm{S}_{\mathrm{i}_{+}}: \text {off; } \mathrm{S}_{\mathrm{i}_{-}}: \text {on }
\end{array}\right.
$$

This performance of the Backstepping controller will be illustrated in the next section by using the simulation results under MATLAB/SIMULINK.

\section{SIMULATION RESULTS AND ANALYSIS}

In this section, simulation results are proposed to demonstrate the performance and robustness of the Backstepping controller. The scenarios used in this simulation are presented in fig. 3. It considers an abrupt irradiation and temperature changes. At $2 \mathrm{~s}$, it proposes also the disturbance of the input capacitor $C_{p}$ amount by $40 \%$ of its principal value and at $2.5 \mathrm{~s}$ the scenarios presents a load current harmonic pollution by $6 \%$ of its fundamental value.

The peak power of the PVG used in this simulation is about $55,940 \mathrm{KW}$ at standard atmospheric conditions..

The nonlinear load could have been any kind of load. In fact, the Backstepping controller is designed independently of the kind of load. In this simulation an inductive load has been used which is supposed to be saturated between $2.5 \mathrm{~s}$ and $3 \mathrm{~s}$.

Table I shows the parameters of the system and the Backstepping controller.

TABLE I. PARAMETRES OF THE SYSTEM AND THE CONTROLLER

\begin{tabular}{|c|c|}
\hline System Parameters & Controller Parameters \\
\hline $\begin{array}{c}\text { Input } \\
\mathrm{C}_{\mathrm{p}}=4700 \mu \mathrm{F}\end{array}$ & $\begin{array}{l}\mathrm{k}_{1}=50 \\
\mathrm{k}_{2}=5000\end{array}$ \\
\hline $\begin{array}{l}\text { Filter inductance: } \mathrm{L}=3 \\
\mathrm{mH} \\
\text { Filter } \quad \text { resistance: } \\
\mathrm{r}=0.002 \Omega\end{array}$ & $\mathrm{k}_{3}=1100$ \\
\hline $\begin{array}{l}\text { Load inductance: } \mathrm{L}_{\mathrm{C}} \\
=20 \mathrm{mH} \\
\quad \text { Load resistance: } \\
\mathrm{R}_{\mathrm{c}}=10 \Omega\end{array}$ & PWM frequency: $10 \mathrm{KHz}$ \\
\hline $\begin{array}{l}\text { Grid voltage: } 380 \mathrm{~V} \\
\text { Grid frequency: } 50 \mathrm{~Hz}\end{array}$ & \\
\hline
\end{tabular}

Fig. 4 shows the PWM references. The notice is that the waveform of these references doesn't contain fluctuation or distortion. Distortion and fluctuation can saturate the inverter switching by produced a high frequency of the PWM control signal.

The behavior of the first output $\frac{\delta \mathrm{P}_{\mathrm{v}}}{\delta \mathrm{v}_{\mathrm{p}}}$ is shown in fig. 5 . It converges asymptotically to zero under the scenarios conditions, which guarantees the achievement of the MPPT with an excellent precision and fast response time and height robustness in front of the system's disturbance as illustrated in fig. 6. The static and dynamic performances of the MPPT are better than those obtained in the references [3-7].

Fig. 7 shows that all the PVG power has been converted on Active Power by the inverter. Indeed, the inverter Active Power converges exactly to the PVG power.

Fig. 8 presents the Active Power flow between the inverter, the grid and the load. It is clear that the load Active Power is stable. This last is supplied by the inverter Active Power in case if it's sufficient and the rest of the inverter Active Power is injected in to the grid. In the other case, the load is supplied by both of the grid and the inverter Active Powers.

Fig. 9 shows the curve of the second output $I_{q}$, which converges very quick to its reference with very good precision. This realization compensates the Reactive Power and harmonic distortion caused by the load under hard conditions as illustrated in fig. 10. This fact is very attractive. Indeed, the Reactive Power in level of grid power flow is null as illustrated in fig. 11. Therefore, the UPF is achieved and the grid current is in phase with the grid voltage under atmospheric condition changes, system parameters disturbance and load current harmonic pollution as demonstrated by fig. 12, fig. 13 and fig. 14 . Moreover, the quality of the wave form of the current injected in to the grid is better when compared to that of the grid current presented in [4-5] and [7]. This last contains an important harmonic distortion which generates power losses and system disturbances.

Fig. 15 shows the grid current harmonic spectrum. It has been verified that using the control strategy proposed, it is possible to eliminate the harmonic distortion of the grid current. 

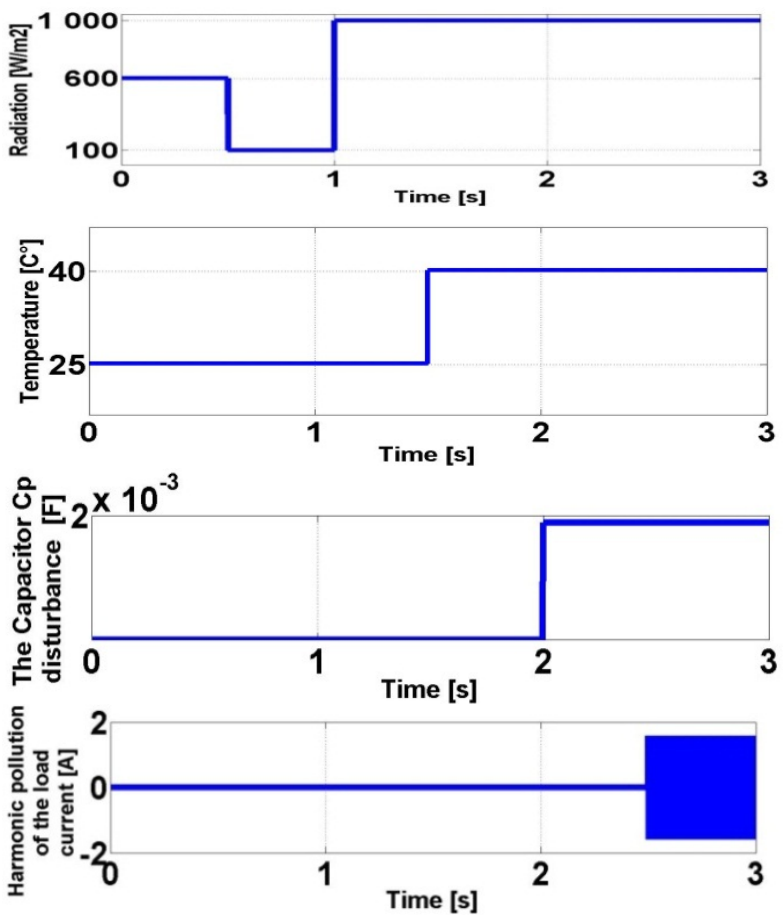

Fig. 3. Simulation scenarios.

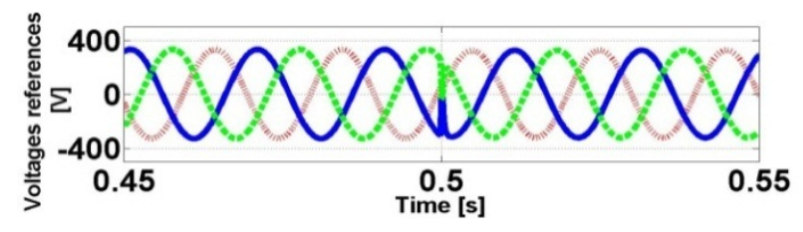

Fig. 4. The PWM references.

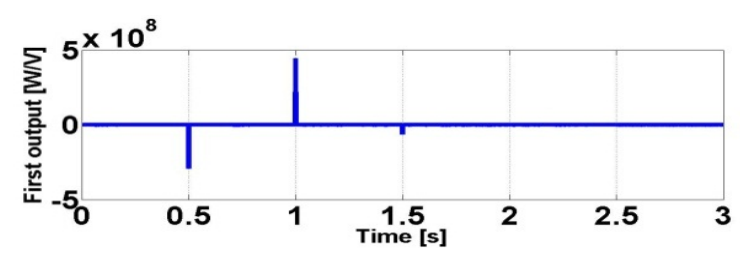

Fig. 5. The curve of the derivative of the PVG power $P_{v}$ with respect to PVG voltage $\mathrm{v}_{\mathrm{p}}$.

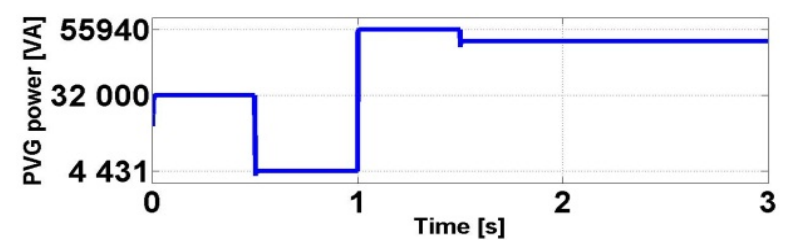

Fig. 6. MPPT achievement under the scenarios conditions.

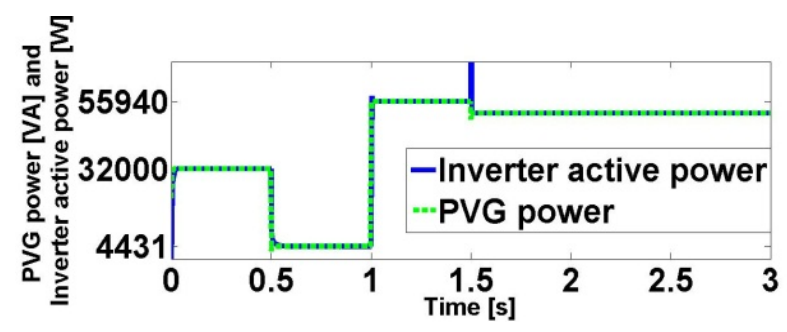

Fig. 7. The behavior of the inverter Active Power in function of the abrupt variation of the PVG power.

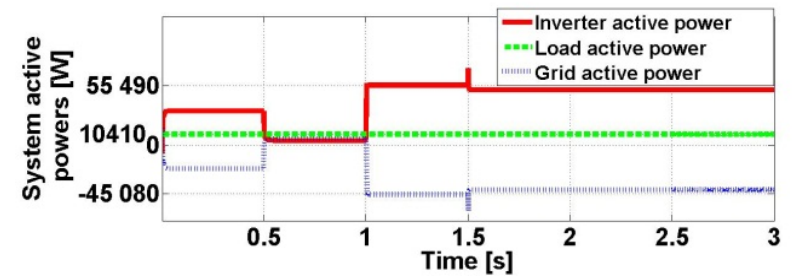

Fig. 8. Active Power exchanges between the inverter, the grid and the load

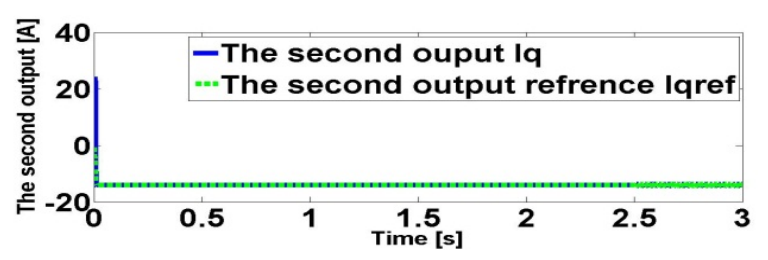

Fig. 9. The curve of the quadratic component current of the inverter $\mathrm{I}_{\mathrm{q}}$.

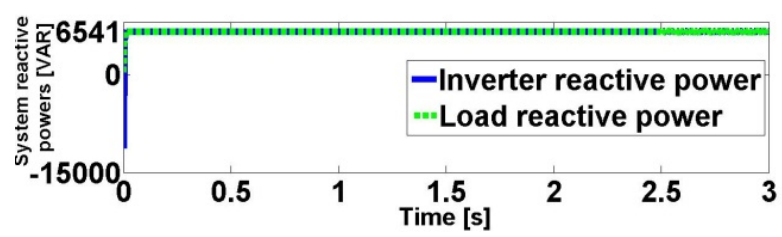

Fig. 10. Compensation of the load Reactive Power by the inverter Reactive Power

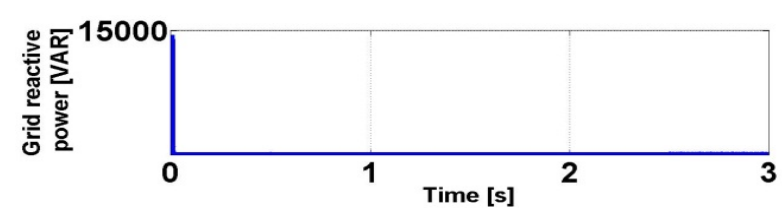

Fig. 11. Grid Reactive Power.

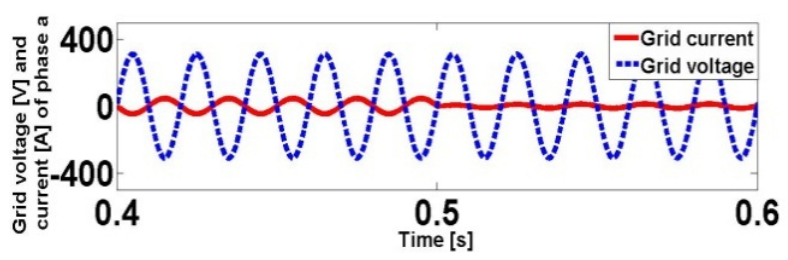

Fig. 12. Phase 'a' of the grid voltage $e_{a}$ and current $i_{g a}$ (achievement of UPF under abrupt changes of the PVG power with very fast response time).

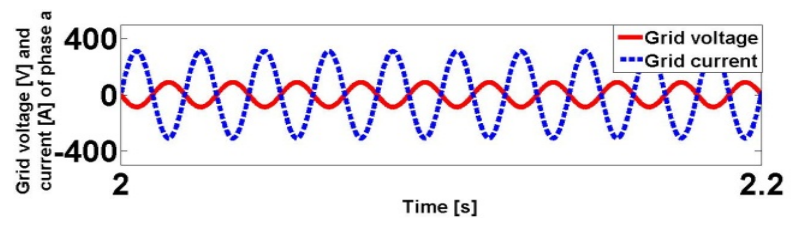

Fig. 13. Fig. 13. Phase 'a' of the grid voltage $e_{a}$ and current $i_{g a}$ (achievement of UPF in presence of the capacitor $\mathrm{C}_{\mathrm{p}}$ disturbance).

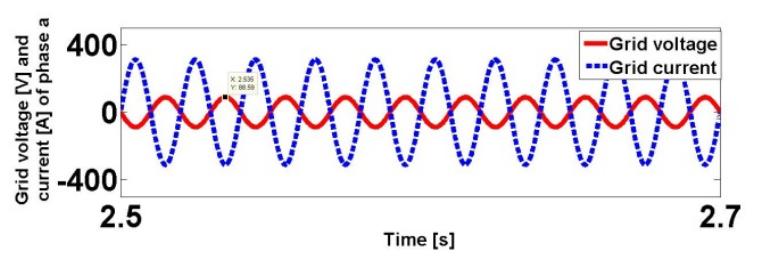

Fig. 14. Phase 'a' of the grid voltage $e_{a}$ and current $i_{g a}$ (achievement of UPF in presence of harmonic pollution of the load current). 


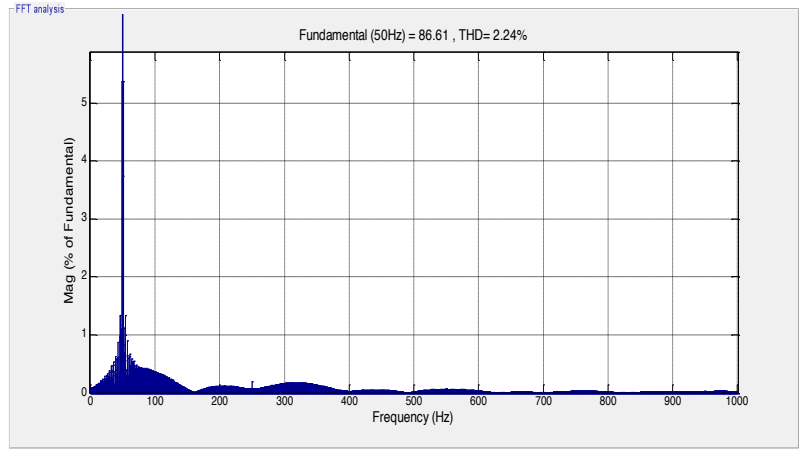

Fig. 15. Grid Current harmonic spectrum in phase ' $a$ '.

\section{CONCLUSION}

This paper presented an advanced control strategy of a three phase load and grid connected PVG system without boost converter. This control strategy is designed by using Backstepping method based on Lyapunov stability approach and dq0 transformation of the PVG system model. The main focus of this controller is to achieve the MPPT and UPF under any conditions. The best advantage of this controller is its robustness in the presence of abrupt atmospheric condition changes and system's disturbance and its inconvenience is the difficulty of the MPPT controller implementation due to the long mathematical equations of the control law, which needs some attention to avoid the errors. Mathematical studied has been proved the Lyapunov stability of the global PVG system and simulation results illustrated that the controller has realized the MPPT and the UPF with a very good precision and fast response time under abrupt conditions changes, which demonstrates the performance and robustness of the proposed controller. The next step will be devoted to assemble a laboratory prototype of a PVG system controlled by this control strategy.

\section{REFERENCES}

1. G. Adamidis, G. Tsengenes and K. Kelesidis, Three Phase Grid Connected Photovoltaic System with Active and Reactive Power Control Using Instantaneous Reactive Power Theory, International Conference on Renewable Energies and Power Quality, Granada Spain, 23-25 March (2010).

2. M. A. Eltawil, Z. Zhao, "Grid - connected photovoltaic power systems: Technical and potential problems-A review", ELSEVIER Renewable and Sustainable Energy Reviews 14, pp. 112-129, (2010).

3. Pradeep K. Khatua, Vigna K. Ramachandaramurthy, Jia Ying Yong, Jagadeesh Pasupuleti, Decoupled Control of Three Phase Grid Connected Solar PV System, IJEAT, Vol. 9, Issue 2, pp. 4218- 4222, December (2019).

4. M. F. Schonardie, R. F. Coelho, R. Schweitzer and D. C. Martins, Control of the active and reactive power using dq0 transformation in a three-phase gridconnected $P V$ system, IEEE International Symposium on Industrial Electronics, pp. 264-269, (2012).

5. M. F. Schonardie, A. Ruseler, R. F. Coelho and D. C. Martins, Three-Phase Grid-Connected PV System With Active And Reactive Power Control Using dq0 Transformation, 9th IEEE/IAS International
Conference on Industry Applications, Sao Paulo, Brazil, 8-10 Nov, (2010)

6. M. B. Bana Sharifian, Y. Mohamadrezapour, M. Hosseinpour and S. Torabzade, Single-Stage Grid Connected Photovoltaic System with Reactive Power Control and Adaptive Predictive Current Controller, Journal of Applied Sciences,vol. 8, ISSN 1812-5654, pp. 1503-1509, (2009).

7. H. Yu, J. Pan and A. Xiang, A multi-function gridconnected $P V$ system with Reactive Power compensation for the grid, ELSEVIER Solar Energy, vol.79, Issue 1, pp. 101-106, july (2005).

8. T. Mingxing, Y. Hong and Y. Dongsheng, Research on Coordinate Transformation of the Three phase circuit, TELKOMNIKA, vol. 11, no. 8, pp. 42224228, August (2013).

9. E. Adzic, V. Porobic, B. Dumnic, N. Celanovic, V.Katic, PLL Synchronization in Grid Connected Converters, The 6th International Conference on Engineering and Technology, Novi Sad, Serbia, May 15-17, no. T.12-1.1, pp. 1-5. (2013).

10. A. El Fadili, F. Giri and A. El Magri, Backstepping Control for Maximum Power Tracking in SinglePhase Grid-Connected Photovoltaic Systems, 11th IFAC International Workshop on Adaptation and Learning in Control and Signal Processing July 3-5, Caen, France, pp. 659-664. (2013).

11. M. Guisser, E. Abdelmounim, M. Aboulfatah and A. EL-Jouni, Nonlinear Observer-Based Control for Grid Connected Photovoltaic System, IOSR Journal of Electrical and Electronics Engineering, vol. 9, eISSN: 2278-1676, p-ISSN: 2320-3331, Issue. 5, pp. 40-52, (2014).

12. M. Guisser, M. Aboulfatah, E. Abdelmounim, H. Medromi and J. Saadi, Nonlinear Control Design for Maximum Power Point Tracking and Unity Power Factor of a Grid-Connected Photovoltaic Renewable Energy Systems, IOSR-JECE, vol .9, Issue 5, pp. 6271, (2014).

13. A. Yahya, H. El Fadil, J. M. Guerrero., F. Giri and H.. Erguig, Three-Phase Grid-Connected of Photovoltaic Generator Using Nonlinear Control. In Proceedings of the IEEE Conference on Control Applications CCA. pp. 879-884, (2014). 